\title{
LIFETIME DISTRIBUTION AND ASSOCIATED INFERENCE OF SYSTEMS WITH MULTIPLE DEGRADATION MEASUREMENTS BASED ON GAMMA PROCESSES
}

\section{WYZNACZANIE ROZKŁADU CZASÓW ŻYCIA ORAZ WNIOSKOWANIE DLA SYSTEMÓW WYMAGAJĄCYCH POMIARÓW WSPÓtISTNIEJĄCYCH DEGRADACJI W OPARCIU O PROCESY GAMMA}

\begin{abstract}
With development of science and technology, many engineering systems take on high reliable characteristic and usually have complex structure and failure mechanisms, with their reliability being evaluated by multiple degradation measurements. In certain physical situations, the degradation of these performance characteristics would be always positive and strictly increasing. Therefore, the gamma process is usually considered as a degradation process due to its independent and non-negative increments properties. In this paper, we suppose that a system has multiple dependent performance characteristics and that their degradation can be modeled by gamma processes. For such a multivariate degradation involving three or more performance characteristics, we propose to use a multivariate Birnbaum-Saunders distribution and its marginal distributions to approximate the reliability function and give the corresponding lifetime distribution. And then, the inferential method for the model parameters is developed. Finally, for an illustration of the proposed model and method, a simulated example is discussed and some computational results are presented.
\end{abstract}

Keywords: multiple degradation, lifetime distribution, gamma process, Birnbaum-Saunders distribution, MCMC method.

\begin{abstract}
Wraz z rozwojem nauki i techniki, powstaje coraz więcej systemów inżynieryjnych o wysokich parametrach niezawodnościowych, które zwykle charakteryzują się złożona struktura i złożonymi mechanizmami uszkodzeń. Ocena niezawodności w przypadku takich systemów wymaga pomiarów wspótwystęujących procesów degradacji. W pewnych sytuacjach fizycznych, degradacja właściwości użytkowych systemu będzie zawsze dodatnia oraz ściśle rosnaca. Proces degradacji jest zwykle procesem gamma, który charakteryzują niezależne i nieujemne przyrosty. W niniejszej pracy, założono, że system ma wiele zależnych charakterystyk pracy oraz że ich degradację można modelować procesem gamma. W przypadkach takiej wielowymiarowej degradacji obejmującej trzy lub więcej charakterystyk pracy zaproponowano zastosowanie rozkladu Birnbauma-Saundersa (uwzględniającego wiele zmiennych) oraz jego rozkładów brzegowych do aproksymacji funkcji niezawodności oraz określania odpowiadajacego jej rozktadu czasu pracy. Opracowano metodę wnioskowania dla parametrów modelu. Wreszcie, dla zilustrowania proponowanego modelu oraz metody, omówiono przykład symulacyjny oraz przedstawiono niektóre wyniki obliczeniowe.
\end{abstract}

Stowa kluczowe: degradacja wspótistniejąca, rozkład czasów życia, proces gamma, rozkład Birnbauma-Saundersa, metoda MCMC.

\section{Introduction}

In Astronautics, Aeronautics, Communications and other fields, there are many high reliable systems. Therefore, how to estimate the reliability of system has become a very significant effort to assess the reliability of critical systems to mitigate the probability of system failure and improve safety environment. Particularly, some systems may experience multiple degradation paths and they are either independent or dependent. When they are dependent, predicting system reliability becomes a challenging problem.

In the available literature, extensive research has been devoted to estimate reliability of systems/products experiencing bivariate or multivariate degradation data. Crk [3] assumed the system failure is governed by several independent mechanisms and presented an effective way to estimate the system's reliability by monitoring each performance characteristic. Wang and Coit [14] described a general modeling and analysis approach for reliability prediction based on degradation modeling, considering multiple degradation measures. $\mathrm{Xu}$ and Zhao [19] also considered this problem and introduced two methods to model and analyze systems with multiple degradation measures. First, they considered the correlation between the degradation measure and the failure event by introducing a probabilistic measure, and then proposed a state-space model to describe the evolution of the degradation process by incorporating both the degradation dynamics and random stress effects. Sari et al. [11] proposed a two-stage reliability model for bivariate degradation data. With the proposed model, not only the marginal reliability but also the system reliability can be assessed. The flexibility of the model to accommodate serial correlation of marginal degradation data, different marginal degradation distribution functions, and dependency between performance characteristics increases the probability to model and analyze the data more accurately compared with models with stricter assumptions. They analyzed the actual experiment data of the LED tube light system and gave some insights into the failure behavior 
of the LED lamps system. Barker and Newby [1] used a multivariate Wiener process to describe the degradation of a complex multicomponent system, and then provide an optimal non-periodic inspection policy for it. Son and Savage [13] proposed a design stage method for assessing performance reliability of systems with multiple time-variant responses due to component degradation. They assume that the system component degradation profiles over time is known and the degradation of the system is related to component degradation using mechanistic models. The cumulative distribution function of time to soft failure has been determined incrementally by summing probabilities of unions of failure sets established from shifted limit-state surfaces over time. They also present a set-theory method for assessing systems reliability where failure events may be described by time-variant parallel and/or series systems [12]. Li et al. [5] discussed a reliability model of a series system with dependent component degradation processes. Mercier et al. [6] discussed a track geometry model based on the observation of two dependent randomly increasing deterioration indicators through a bivariate gamma process constructed by trivariate reduction, and then give the intervention scheduling of a railway track. Pan and Balakrishnan [8] proposed a bivariate constant-stress accelerated degradation test model based on Wiener processes and Copulas. And the corresponding copula parameter is a function of the stress level that can be described by logistic function. Particularly, it is worth mentioning that Zhou et al. [20] proposed a bivariate degradation model based on copulas when a product has two performance characteristics and they can be governed by gamma processes. Furthermore, Pan and Balakrishnan [9] introduced the reliability model for the degradation of products with two performance characteristics by assuming that the performance characteristics are governed by gamma processes. In that case, they used a bivariate Birnbaum-Saunders distribution and its marginal distributions to approximate the reliability of the product. Wang et al. [17] gave the reliability equations when typical degradation and shocks are involved. The failure modes included catastrophic failure, degradation and failure due to shocks. Furthermore, they constructed a system reliability model on competitive failure processes under fuzzy degradation data and evaluated the proposed model by multi-state system reliability theory [18]. Wang and Pham [15] proposed a dependent competing risk model for a deteriorating system subject to shock processes, and a maintenance model involving imperfect maintenance actions. They also develop a dependent competing risk model for systems subject to multiple degradation processes and random shocks using time-varying copulas [16]. Peng et al. [10] presented a comprehensive Bayesian framework for the integration of multilevel heterogeneous data sets, including the pass-fail data, lifetime data and degradation data at different system levels, which gave a more practical tool for real engineering applications.

This paper extends the work of Pan and Balakrishnan [9] and assumes that a system has multiple dependent performance characteristics and that their degradation can be modeled by gamma processes. For such a multivariate degradation involving three or more performance characteristics, we propose to use a multivariate Birnbaum-Saunders distribution and its marginal distributions to approximate the reliability function and give the corresponding lifetime distribution.

The rest of the paper is organized as follows. In Section 2, the formulation of systems with multiple degradation measurements is given. In Section 3, the lifetime distribution and associated inference for such systems are presented. Section 4 discusses the estimation of model parameters. A simulated example is given to illustrate the model and method proposed in Section 5. Finally, some concluding remarks are made in Section 6.

\section{Formulation of Systems with Multiple Degradation Measurements}

\subsection{Assumptions}

(1) All the degradation paths of the systems are governed by gamma processes. Let $G_{k}(t)$ denotes the $k^{\text {th }}$ degradation path with shape parameter $v_{k}$ and scale parameter $u_{k}$, where $t \geq 0$, and $G_{k}(0)$. Here, $k=1, \cdots, K$, and $K$ is the number of the degradation paths. For a given $t$ and $\Delta t$,

$$
\Delta G_{k}(t) \sim G a\left(v_{k} \Delta t, u_{k}\right)
$$

where $\Delta G_{k}(t)=G_{k}(t+\Delta t)-G_{k}(t)$, and $G a\left(v_{k} \Delta t, u_{k}\right)$ is a gamma distribution with shape parameter $v_{k} \Delta t$ and scale parameter $u_{k}$. The probability density function (PDF) of a random variable $X$ having a gamma distribution with shape parameter $v$ and scale parameter $u$ can be given by:

$$
g(x)=\frac{1}{\Gamma(v) u^{v}} x^{v-1} e^{-\frac{x}{u}} I_{(0, \infty)}(x),
$$

where:

$$
I_{(0, \infty)}(x)= \begin{cases}1 & \text { if } x \in(0, \infty) \\ 0 & \text { if } x \notin(0, \infty)\end{cases}
$$

and $\Gamma(v)=\int_{0}^{\infty} x^{\nu-1} e^{-x} d x$ is the complete gamma function.

(2) The degradation paths are not pairwise independent and the dependence of all the degradation paths can be described by variancecovariance matrix.

(3) All observations of the degradation paths are made at the same predetermined times (case of balanced data), and the measurement frequency is a constant denoted as $\Delta t$.

(4) In the case of different predetermined measurement times of the degradation paths, the dependency can be ignored, that is, we can consider $\Delta G_{k_{1}}\left(t_{j}\right)$ and $\Delta G_{k_{2}}\left(t_{j^{\prime}}\right)$ to be independent, when,$j \neq j^{\prime}$ where $k_{1}=1, \cdots, K, k_{2}=1, \cdots, K, j=1, \cdots, M, j^{\prime}=1, \cdots, M$.

\subsection{Formulation of the Problem}

For degradation paths involving independent nonnegative increments, gamma processes are more suitable for describing the deterioration of the system. In the present work, we suppose that a system has $K$ degradation paths which are dependent each other and all the degradation paths are governed by gamma processes. For such a system, $m$ measurements for all the paths are observed up to the termination time $T$, which results in degradation measurements $\boldsymbol{G}\left(t_{j}\right)=\left(G_{1}\left(t_{j}\right), \cdots, G_{K}\left(t_{j}\right)\right)^{\prime}$ corresponding to time $t_{j}, j=1, \cdots, M$. In general, the multiple degradation data for this model can be presented in the form:

$$
\boldsymbol{G}_{K \times M}=\left(\begin{array}{ccc}
G_{1}\left(t_{1}\right) & \cdots & G_{1}\left(t_{M}\right) \\
\vdots & \ddots & \vdots \\
G_{K}\left(t_{1}\right) & \cdots & G_{K}\left(t_{M}\right)
\end{array}\right)
$$


For $k=1, \cdots, K$, let:

$$
\Delta G_{k}\left(t_{j}\right)=G_{k}\left(t_{j}\right)-G_{k}\left(t_{j-1}\right), t_{0}=0
$$

For each degradation path, by the independent increment property of the gamma process, we have independent but non-identical random variables:

$$
\Delta G_{k}\left(t_{j}\right) \sim G a\left(v_{k} \Delta t, u_{k}\right), \quad \Delta t=t_{j}-t_{j-1} .
$$

So, the PDF of $\Delta G_{k}\left(t_{j}\right)$ is:

$$
g_{k}\left(\Delta G_{k}\left(t_{j}\right)\right)=\frac{1}{\Gamma\left(v_{k} \Delta t\right)\left(u_{k}\right)^{v_{k} \Delta t}}\left(\Delta G_{k}\left(t_{j}\right)\right)^{v_{k} \Delta t-1} \cdot \exp \left(-\frac{\Delta G_{k}\left(t_{j}\right)}{u_{k}}\right),
$$

with the corresponding mean and variance given by:

$$
E\left[\Delta G_{k}\left(t_{j}\right)\right]=u_{k} v_{k} \Delta t, \operatorname{Var}\left[\Delta G_{k}\left(t_{j}\right)\right]=u_{k}^{2} v_{k} \Delta t
$$

The degradation increments of the paths, $\Delta G_{k}\left(t_{j}\right)$ can be normalized as:

$$
Y_{k j}=\frac{\Delta G_{k}\left(t_{j}\right)-u_{k} v_{k} \Delta t}{\sqrt{v_{k} \Delta t} u_{k}}
$$

For $\boldsymbol{Y}_{\mathrm{j}}=\left(Y_{1 j}, \cdots, Y_{K j}\right)$, it is known that they are i.i.d. vectors satisfying:

$$
E\left(Y_{k j}\right)=0, \quad \operatorname{Var}\left(Y_{k j}\right)=1,
$$

with correlation coefficient being:

$$
\operatorname{corr}\left(Y_{k_{1} j}, Y_{k_{2} j}\right)=\operatorname{corr}\left(\Delta G_{k_{1}}\left(t_{j}\right), \Delta G_{k_{2}}\left(t_{j}\right)\right)=\rho_{k_{1} k_{2}} .
$$

For each path, we know that the distribution of the first passage time to its threshold value can be approximated by Birnbaum-Saunders distribution [2]. Pan and Balakrishnan [9] gave the lifetime distribution of product with two dependent performance characteristics using bivariate Birnbaum-Saunders distribution. In the following section, we will discuss the lifetime distribution and associated inference of systems with any $K$ degradation paths, where $K \geq 3$.

\section{Lifetime Distribution and Associated Inference}

Let $T_{\mathrm{k}}$ be the first passage times of $k^{\text {th }}$ degradation paths with the threshold values $\omega_{k}, k=1, \cdots, K$. Any path of the $K$ degradation pathes exceeds its threshold value, the system fails. Therefore, the system's reliability at time $t$ can be expressed as:

$$
\begin{aligned}
R(t) & =P\left(T_{1}>t, \cdots, T_{K}>t\right) \\
& =P\left(G_{1}(t)<\omega_{1}, \cdots, G_{K}(t)<\omega_{K}\right) \\
& =P\left(\sum_{j=1}^{M} \Delta G_{1}\left(t_{j}\right)<\omega_{1}, \cdots, \sum_{j=1}^{M} \Delta G_{K}\left(t_{j}\right)<\omega_{K}\right) \\
& =P\left(\sum_{j=1}^{M} \frac{\Delta G_{1}\left(t_{j}\right)-v_{1} u_{1} \Delta t}{\sqrt{v_{1} \Delta t} u_{1}}<\omega_{1}, \cdots, \sum_{j=1}^{M} \frac{\Delta G_{K}\left(t_{j}\right)-v_{K} u_{K} \Delta t}{\sqrt{v_{K} \Delta t} u_{K}}<\omega_{K}\right) \\
& =P\left(\frac{1}{\sqrt{M}} \sum_{j=1}^{M} Y_{1 j}<\frac{\omega_{1}-v_{1} u_{1} t}{\sqrt{v_{1} t} u_{1}}, \cdots, \frac{1}{\sqrt{M}} \sum_{j=1}^{M} Y_{K j}<\frac{\omega_{K}-v_{K} u_{K} t}{\sqrt{v_{K} t} u_{K}}\right) .
\end{aligned}
$$

According to multidimensional central limit theorem and the property of covariance, (6) can be approximated by:

$$
R(t)=\Phi_{K}\left(\frac{\omega_{1}-v_{1} u_{1} t}{\sqrt{v_{1} t} u_{1}}, \cdots, \frac{\omega_{K}-v_{K} u_{K} t}{\sqrt{v_{K} t} u_{K}} ; 0, \Sigma\right),
$$

where:

$$
\Sigma=\left(\begin{array}{cccc}
\operatorname{Var}\left(Y_{11}\right) & \operatorname{Cov}\left(Y_{11}, Y_{21}\right) & \cdots & \operatorname{Cov}\left(Y_{11}, Y_{K 1}\right) \\
\operatorname{Cov}\left(Y_{21}, Y_{11}\right) & \operatorname{Var}\left(Y_{21}\right) & \cdots & \operatorname{Cov}\left(Y_{21}, Y_{K 1}\right) \\
\vdots & \vdots & \ddots & \vdots \\
\operatorname{Cov}\left(Y_{K 1}, Y_{11}\right) & \operatorname{Cov}\left(Y_{K 1}, Y_{21}\right) & \cdots & \operatorname{Var}\left(Y_{K 1}\right)
\end{array}\right)
$$

and $\Phi_{K}$ is the multivariate normal distribution of a $K$-dimensional random vector. In terms of (4) and (5), $\boldsymbol{\Sigma}$ can be rewritten as:

$$
\Sigma=\left(\begin{array}{cccc}
1 & \rho_{12} & \cdots & \rho_{1 K} \\
\rho_{21} & 1 & \cdots & \rho_{2 K} \\
\vdots & \vdots & \ddots & \vdots \\
\rho_{K 1} & \rho_{K 2} & \cdots & 1
\end{array}\right)
$$

Let:

$$
\begin{gathered}
\Sigma_{\left(k_{1}, \cdots, k_{l}\right)}=\left(\begin{array}{cccc}
1 & \rho_{k_{1} k_{2}} & \cdots & \rho_{k_{1} k_{l}} \\
\rho_{k_{2} k_{1}} & 1 & \cdots & \rho_{k_{2} k_{l}} \\
\vdots & \vdots & \ddots & \vdots \\
\rho_{k_{l} k_{1}} & \rho_{k_{l} k_{2}} & \cdots & 1
\end{array}\right)_{l \times l}, \\
\Sigma_{\left(k_{1}, \cdots, k_{l}\right)}^{-k_{m}}=\Sigma_{\left(k_{1}, \cdots, k_{m-1}, k_{m+1}, \cdots, k_{l}\right)} .
\end{gathered}
$$

(7) can, therefore, be represented as: 


$$
\begin{aligned}
R(t) \cong & 1-\sum_{k=1}^{K} \Phi_{1}\left(\frac{\omega_{K}-v_{K} u_{K} t}{\sqrt{v_{K} t} u_{K}}\right) \\
& +\sum_{k_{1}=1}^{K-1} \sum_{k_{2}=k_{1}+1}^{K} \Phi_{2}\left(\frac{v_{k_{1}} u_{k_{1}} t-\omega_{k_{1}}}{\sqrt{v_{k_{1}} t} u_{k_{1}}}, \frac{v_{k_{2}} u_{k_{2}} t-\omega_{k_{2}}}{\sqrt{v_{k_{2}} t} u_{k_{2}}} ; 0, \Sigma_{\left(k_{1}, k_{2}\right)}\right) \\
& +\cdots+(-1)^{K} \Phi_{K}\left(\frac{v_{1} u_{1} t-\omega_{1}}{\sqrt{v_{1} t} u_{1}}, \cdots, \frac{v_{K} u_{K} t-\omega_{K}}{\sqrt{v_{K} t} u_{K}} ; 0, \Sigma_{(1, \cdots, K)}\right) \\
& =1-\sum_{k=1}^{K} \Phi_{1}\left(\frac{1}{\alpha_{k}}\left(\sqrt{\frac{t}{\beta_{k}}}-\sqrt{\frac{\beta_{k}}{t}}\right)\right) \\
& +\sum_{k_{1}=1 k_{2}=k_{1}+1}^{K-1} \Phi_{2}^{K}\left(\frac{1}{\alpha_{k_{1}}}\left(\sqrt{\frac{t}{\beta_{k_{1}}}}-\sqrt{\frac{\beta_{k_{1}}}{t}}\right), \frac{1}{\alpha_{k_{2}}}\left(\sqrt{\frac{t}{\beta_{k_{2}}}}-\sqrt{\frac{\beta_{k_{2}}}{t}}\right) ; 0, \Sigma_{\left(k_{1}, k_{2}\right)}\right) \\
& +\cdots+(-1)^{K} \Phi_{K}\left(\frac{1}{\alpha_{1}}\left(\sqrt{\frac{t}{\beta_{1}}}-\sqrt{\frac{\beta_{1}}{t}}\right), \cdots, \frac{1}{\alpha_{K}}\left(\sqrt{\frac{t}{\beta_{K}}}-\sqrt{\frac{\beta_{K}}{t}}\right) ; 0, \Sigma_{(1, \cdots, K)}\right)
\end{aligned}
$$

where: $\alpha_{k}=\frac{1}{\sqrt{\omega_{k} / u_{k}}}$, and $\beta_{k}=\frac{\omega_{k}}{v_{k} u_{k}}, k=1, \cdots, K$. Kundu et al.

[4] proposed a bivariate Birnbaum-Saunders distribution in their work. Here, we can extend their result to any -dimensional random vector $\left(T_{1}, T_{2}, \cdots, T_{k}\right)$, which have the multivariate Birnbaum-Saunders distribution, if the joint cumulative distribution function of $\left(T_{1}, T_{2}, \cdots, T_{k}\right)$ can be expressed as:

$$
\begin{aligned}
& \mathrm{P}\left(T_{1}<t_{1}, \cdots, T_{K}<t_{K}\right) \\
& =\Phi_{K}\left(\frac{1}{\alpha_{1}}\left(\sqrt{\frac{t}{\beta_{1}}}-\sqrt{\frac{\beta_{1}}{t}}\right), \cdots, \frac{1}{\alpha_{K}}\left(\sqrt{\frac{t}{\beta_{K}}}-\sqrt{\frac{\beta_{K}}{t}}\right) ; 0, \Sigma_{(1, \cdots, K)}\right) .
\end{aligned}
$$

According to (9), it is easy to obtain the lifetime distribution of $T, F(t)=1-R(t)$, and we find that $F(t)$ can be approximated by multivariate Birnbaum-Saunders distribution of a $K$-dimensional random vector and all its marginal distributions.

Let:

$$
U_{k}(t)=\frac{1}{\alpha_{k}}\left(\sqrt{\frac{t}{\beta_{k}}}-\sqrt{\frac{\beta_{k}}{t}}\right)
$$

and:

$$
\begin{aligned}
& \boldsymbol{U}_{\left(k_{1}, \cdots, k_{l}\right)}(t)=\left(U_{k_{1}}(t), \cdots, U_{k_{l}}(t)\right) \\
& \boldsymbol{U}_{\left(k_{1}, \cdots, k_{l}\right)}^{-k_{m}}(t)=\boldsymbol{U}_{\left(k_{1}, \cdots, k_{m-1}, k_{m+1}, \cdots, k_{l}\right)}(t), \\
& \boldsymbol{\Omega}_{\left(k_{1}, \cdots, k_{l}\right)}=\left\{\left(-\infty, U_{k_{1}}(t)\right), \cdots,\left(-\infty, U_{k_{l}}(t)\right)\right\}, \\
& \Omega_{\left(k_{1}, \cdots, k_{l}\right)}^{-k_{m}}=\boldsymbol{\Omega}_{\left(k_{1}, \cdots, k_{m-1}, k_{m+1}, \cdots, k_{l}\right)}, \\
& \boldsymbol{x}_{\left(k_{1}, \cdots, k_{l}\right)}=\left(x_{k_{1}}, \cdots, x_{k_{l}}\right), \\
& \boldsymbol{x}_{\left(k_{1}, \cdots, k_{l}\right)}^{-k_{m}}=\boldsymbol{x}_{\left(k_{1}, \cdots, k_{m-1}, k_{m+1}, \cdots, k_{l}\right)}, \\
& \rho_{\left(k ; k_{1}, \cdots, k_{l}\right)}=\left(\rho_{k k_{1}}, \cdots, \rho_{k k_{l}}\right), \\
& \rho_{\left(k ; k_{1}, \cdots, k_{l}\right)}^{-k_{m}}=\boldsymbol{\rho}_{\left(\boldsymbol{k} ; k_{1}, \cdots, k_{m-1}, k_{m+1}, \cdots, k_{l}\right)} .
\end{aligned}
$$

According to (9), it can be expressed as:

$$
\begin{aligned}
R(t)= & \left.1-\sum_{k=1}^{K} \Phi_{1}\left(U_{k}(t)\right)+\sum_{k_{1}=1 k_{2}=k_{1}+1}^{K-1} \sum_{2}^{K} \Phi_{\left(k_{1}, k_{2}\right)}(t) ; 0, \Sigma_{\left(k_{1}, k_{2}\right)}\right) \\
& +\cdots+(-1)^{K} \Phi_{K}\left(U_{(1, \cdots, K)}(t) ; 0, \Sigma_{(1, \cdots, K)}\right) .
\end{aligned}
$$

Therefore, we can obtain the PDF of the lifetime of the system as follows:

$$
\begin{aligned}
f(t) & =-\frac{d R(t)}{d t} \\
& =\sum_{k=1}^{K} f_{k}\left(t ; \alpha_{k}, \beta_{k}\right)-\sum_{k_{1}=1 k_{2}=k_{1}+1}^{K-1} \frac{d \Phi_{2}\left(\boldsymbol{U}_{\left(k_{1}, k_{2}\right)}(t) ; 0, \Sigma_{\left(k_{1}, k_{2}\right)}\right)}{d t} \\
& +\cdots+(-1)^{(K+1)} \frac{d \Phi_{K}\left(U_{(1, \cdots, K)}(t) ; 0, \Sigma_{(1, \cdots, K)}\right)}{d t}
\end{aligned}
$$

where: $f_{k}\left(t ; \alpha_{k}, \beta_{k}\right), k=1, \cdots, K$, is the PDF of Birnbaum-Saunders distribution given by:

$f_{k}\left(t ; \alpha_{k}, \beta_{k}\right)=\frac{1}{2 \sqrt{2 \pi} \alpha_{k} \beta_{k}}\left[\left(\frac{\beta_{k}}{t}\right)^{\frac{1}{2}}+\left(\frac{\beta_{k}}{t}\right)^{\frac{3}{2}}\right] \exp \left[-\frac{1}{2 \alpha_{k}^{2}}\left(\frac{t}{\beta_{k}}-2+\frac{\beta_{k}}{t}\right)\right], t>0$

We know that:

$\Phi_{K}\left(U_{(1, \cdots, K)}(t) ; 0, \Sigma_{(1, \cdots, K)}\right)=\int_{\Omega\left(k_{1}, \ldots, k_{l}\right)}(2 \pi)^{-\frac{K}{2}}\left|\Sigma_{(1, \cdots, K)}\right|^{-\frac{1}{2}} \exp \left\{-\frac{1}{2} x^{\prime}\left(\Sigma_{(1, \cdots, K)}\right)^{-1} x\right\} d x_{(1, \cdots, K)}$.

Define

$p\left(x_{k}\right)=\int_{\Omega_{\left(k_{1}, \cdots, k_{l}\right)}^{-k}}(2 \pi)^{-\frac{K}{2}}\left|\Sigma_{(1, \cdots, K)}\right|^{-\frac{1}{2}} \exp \left\{-\frac{1}{2} \boldsymbol{x}^{\prime}\left(\Sigma_{(1, \cdots, K)}\right)^{-1} \boldsymbol{x}\right\} d \boldsymbol{x}_{(1, \cdots, K)}^{-k}$,

then, we have:

$$
\frac{d \Phi_{K}\left(\boldsymbol{U}_{(1, \cdots, K)}(t) ; 0, \Sigma_{(1, \cdots, K)}\right)}{d t}=\sum_{k=1}^{K} \frac{d U_{k}(t)}{d t} p\left(U_{k}(t)\right) .
$$

Furthermore, we can obtain:

$$
p\left(U_{k}(t)\right)=P\left(\boldsymbol{x}_{(1, \cdots, K)}^{-k} \mid x_{k}=U_{k}(t)\right) \phi_{1}\left(U_{k}(t)\right) .
$$

In terms of the property of multivariate normal distribution, the conditional distribution $P\left(\boldsymbol{x}_{(1, \cdots, K)}^{-k} \mid x_{k}=U_{k}(t)\right)$ is multivariate normal distribution with mean and covariance matrix:

$$
\begin{aligned}
& \tilde{\mu}_{(1, \cdots, K)}^{-k},=\rho_{(k ; 1, \cdots, K)}^{-k} U_{k}(t), \\
& \tilde{\Sigma}_{(1, \cdots, K)}^{-k}=\Sigma_{(1, \cdots, K)}^{-k}-\left(\rho_{(k ; 1, \cdots, K)}^{-k}\right)^{\prime} \rho_{(k ; 1, \cdots, K)}^{-k} .
\end{aligned}
$$

Thus,

$$
p\left(U_{k}(t)\right)=\phi_{1}\left(U_{k}(t)\right) \Phi_{K-1}\left(\boldsymbol{U}_{(1, \cdots, K)}^{-k}(t) ; \tilde{\mu}_{(1, \cdots, K)}^{-k}, \tilde{\Sigma}_{(1, \cdots, K)}^{-k}\right),
$$


and so:

$$
\begin{aligned}
& \frac{d \Phi_{K}\left(\boldsymbol{U}_{(1, \cdots, K)}(t) ; 0, \Sigma_{(1, \cdots, K)}\right)}{d t} \\
& =\sum_{k=1}^{K} \frac{d U_{k}(t)}{d t} \phi_{1}\left(U_{k}(t)\right) \Phi_{K-1}\left(\boldsymbol{U}_{(1, \cdots, K)}^{-k}(t) ; \tilde{\mu}_{(1, \cdots, K)}^{-k}, \tilde{\Sigma}_{(1, \cdots, K)}^{-k}\right) \\
& =\sum_{k=1}^{K} f_{k}\left(t ; \alpha_{k}, \beta_{k}\right) \Phi_{K-1}\left(\boldsymbol{U}_{(1, \cdots, K)}^{-k}(t) ; \tilde{\mu}_{(1, \cdots, K)}^{-k}, \tilde{\Sigma}_{(1, \cdots, K)}^{-k}\right) .
\end{aligned}
$$

Similarly, for $, \forall l, 1<l<K$, we obtain:

$$
\begin{aligned}
& \frac{d \Phi_{l}\left(\boldsymbol{U}_{\left(k_{1}, \cdots, k_{l}\right)}(t) ; 0, \Sigma_{\left(k_{1}, \cdots, k_{l}\right)}\right)}{d t} \\
& =\sum_{m-1}^{l} f_{k_{m}}\left(t ; \alpha_{k_{m}}, \beta_{k_{m}}\right) \Phi_{l-1}\left(\boldsymbol{U}_{\left(k_{1}, \cdots, k_{l}\right)}^{-k_{m}}(t) ; \tilde{\mu}_{\left(k_{1}, \cdots, k_{l}\right)}^{-k_{m}}, \tilde{\Sigma}_{\left(k_{1}, \cdots, k_{l}\right)}^{-k_{m}}\right)
\end{aligned}
$$

According to (12) and (13), (11) can be rewritten as:

$$
\begin{aligned}
f(t) & =-\frac{d R(t)}{d t} \\
& =\sum_{k=1}^{K} f_{k}\left(t ; \alpha_{k}, \beta_{k}\right) \\
& -\sum_{k_{1}=1}^{K-1} \sum_{k_{2}=k_{1}+1}^{K} \sum_{m=1}^{2} f_{k_{m}}\left(t ; \alpha_{k_{m}}, \beta_{k_{m}}\right) \Phi_{1}\left(\boldsymbol{U}_{\left(k_{1}, k_{2}\right)}^{-k_{m}}(t) ; \tilde{\mu}_{\left(k_{1}, k_{2}\right)}^{-k_{m}}, \tilde{\Sigma}_{\left(k_{1}, k_{2}\right)}^{-k_{k_{2}}}\right) \\
& \left.+\cdots+(-1)^{(K+1)} \sum_{k=1}^{K} f_{k}\left(t ; \alpha_{k}, \beta_{k}\right) \Phi_{K-1}\left(\boldsymbol{U}_{(1, \cdots, K)}^{-k}(t) ; \tilde{\mu}_{(1, \cdots, K)}^{-k}, \tilde{\Sigma}_{(1, \cdots, K)}^{-k}\right)\right)
\end{aligned}
$$

\section{Estimation of Model Parameters}

In this section, we discuss the estimation of the model parameters. The procedure consists of two steps. Firstly, we can estimate the cov-

ariance matrix $\boldsymbol{\Sigma}$. Let, $\Delta \boldsymbol{G}\left(t_{j}\right)=\left(\Delta G_{1}\left(t_{j}\right), \cdots, \Delta G_{K}\left(t_{j}\right)\right)^{\prime}, j=1, \cdots, M$ be the multivariate degradation increment vector. According to (5) and (8), the estimator of $\Sigma, \tilde{\Sigma}$ can be obtained by $\Delta \boldsymbol{G}\left(t_{j}\right)$. Its MLE for a sample of observations is:

$$
\hat{\Sigma} \frac{1}{M} \sum_{j=1}^{M}\left(\Delta \boldsymbol{G}\left(t_{j}\right)-\Delta \overline{\boldsymbol{G}}(t)\right)\left(\Delta \boldsymbol{G}\left(t_{j}\right)-\Delta \overline{\boldsymbol{G}}(t)\right)^{\prime},
$$

where $\Delta \overline{\boldsymbol{G}}(t)=\left(\Delta \bar{G}_{1}(t), \cdots, \Delta \bar{G}_{K}(t)\right)^{\prime}$, and $\Delta \bar{G}_{k}(t)=\frac{1}{M} \sum_{j=1}^{M} \Delta G_{k}\left(t_{j}\right)$.

$$
\text { As described in Section 3, for }\left(\frac{1}{\sqrt{M}} \sum_{j=1}^{M} Y_{1 j}, \cdots, \frac{1}{\sqrt{M}} \sum_{j=1}^{M} Y_{K j}\right) \text {, }
$$

its joint distribution can be approximated by multivariate normal distribution according to (6) and (7), and follows gamma distribution with shape parameter $v_{k} \Delta t$ and scale parameter. Thus, the log-likelihood function based on measurements on the $K$ degradation paths is given by:

$$
\ln L=\log \phi_{K}\left[\frac{1}{\sqrt{M}} \sum_{j=1}^{M} Y_{1 j}, \cdots, \frac{1}{\sqrt{M}} \sum_{j=1}^{M} Y_{K j} ; 0, \hat{\Sigma}\right]+\sum_{k=1}^{K} \sum_{j=1}^{M} \log g_{k}\left(\Delta G_{k}\left(t_{j}\right)\right) .
$$

From (16), we observe that the model is quite complicated from a computational viewpoint. For this reason, we make use of the Bayesian MCMC method for estimating the model parameters. In most practical applications in which Bayesian approach is used, it is difficult to compute analytically the posterior distribution. The MCMC method can be used to generate a sample from the posterior distribution large enough based on a Markov Chain so that any desired feature of the posterior distribution can be accurately estimated. Here, we assume that the prior distributions of all the unknown parameters are non-informative and we then utilize Matlab MCMC toolbox to implement the Metropolis-Hastings sampling after which we can estimate the model parameters of interest.

\section{Simulated Example}

To illustrate the model and inference method proposed in the preceding sections, we give a simulated example in this section. Firstly, the algorithm to simulate the data for multiple degradation measurements based on gamma processes is presented. And then, the estimation of the model parameters will be obtained according to the procedure in section 4 .

\subsection{Simulation of Data}

Recently, copulas have become popular in simulation models. Copulas are functions that describe dependencies among variables, and provide a way to create distributions to model correlated multivariate data. About the details of copula function, please see the book written by Nelsen [7]. Using a copula, a data analyst can construct a multivariate distribution by specifying marginal univariate distributions, and choosing a particular copula to provide a correlation structure between variables. Bivariate distributions, as well as distributions in higher dimensions, are possible. To simulate dependent multivariate data using a copula, we have seen that we need to specify the copula family (we use Gaussian copula here), the rank correlations among variables, and the marginal distributions for each variable.

In this simulated example, we assume that a system with three degradation paths and the corresponding simulation parameters are denoted as, where and are the shape and scale parameters of gamma distributions, respectively, and is the kendall's tau which describes the rank correlations among the three degradation paths. There is a simple 1-1 mapping between Kendall's tau and the linear correlation coefficient:

$$
\tau=(2 / \pi) \times \arcsin (\Sigma) \text { or } \Sigma=\sin (\tau \times \pi / 2) \text {. }
$$

Suppose that $\left(t_{j}\right), 1 \leq \mathrm{j} \leq 500$ time increments are random chosen with similar magnitude as the data of system degradation. Let $v=(0.04,0.05,0.06), \quad u=(0.05,0.04,0.025)$ and $\tau=(1,0.6,0.4$; $0.6,1,0.3 ; 0.4,0.3,1)$. According to $(17)$, it is easy to know that $\Sigma$ $=(1,0.8090,0.5878 ; 0.8090,1,0.4540 ; 0.5878,0.4540,1)$, and let $\rho=(0.8090,0.5878,0.4540)$. Then, 500 values of degradation measurements can be simulated according to the following procedure.

(1) specify the copula family as Gaussian copula with parameters $(0, \Sigma)$

(2) the rank correlations among the triple degradation paths are $\tau$;

(3) the marginal distribution of the increments for $i^{\text {th }}$ degradation path is gamma distribution with parameters $\left(v_{i}, u_{i}\right), i=1,2,3$.

Therefore, the correlated multivariate data $\Delta \mathbf{G}$ that we need can be generated by Matlab as follows. And then, the triple simulated degradation paths are obtained easily.

$Z=\operatorname{mvnrnd}([0,0,0], \Sigma, 500)$;

$U=\operatorname{normcdf}(Z, 0,1)$;

$\Delta \boldsymbol{G}=[\operatorname{gaminv}(U(:, 1), v(1), u(1)), \operatorname{gaminv}(\mathrm{U}(:, 2), v(2), u(2)), \operatorname{gaminv}(U(:, 3), v(3), u(3))]$ 


\subsection{Estimation of Parameters}

According to the model parameters settings above, we generate 500 data sets to validate the model and method proposed. The parameters are estimated by using Matlab MCMC toolbox. For each group data, 5000 realizations of the parameters are from the posterior, and the last 4000 are used for estimation of the parameters. Therefore, we can obtain 500 groups estimated parameters. Figure 1 gives the hist graphs of the estimated parameters. And then, the mean, standard
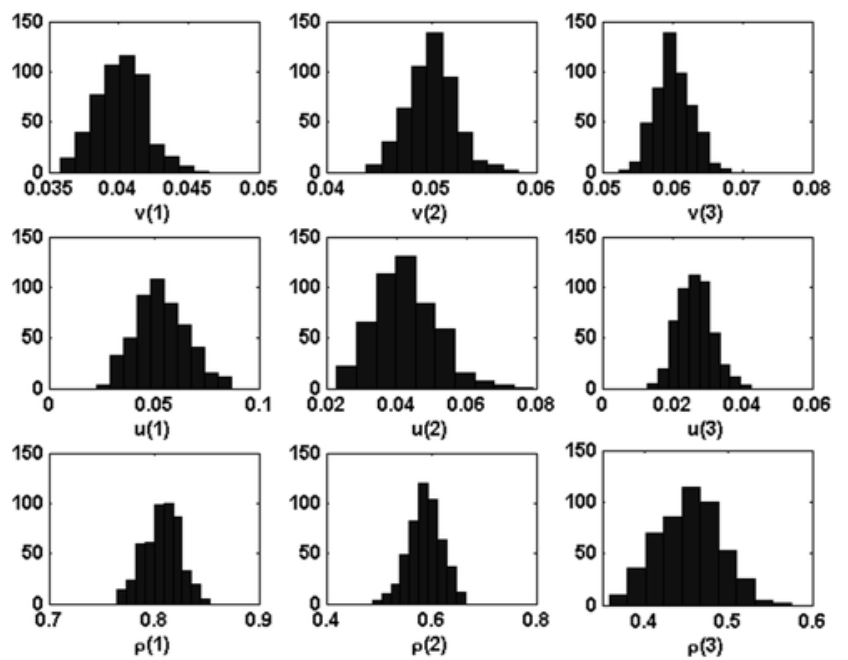

Fig. 1. The hist graphs of the estimated parameters

Table 1. Model parameter estimation results

\begin{tabular}{|c|c|c|c|c|}
\hline \multirow{2}{*}{ Parameters } & \multicolumn{3}{|c|}{ Results } & \multirow{2}{*}{ True value } \\
\hline & mean & std & RMSE & \\
\hline$v(1)$ & 0.0401 & $1.7345 \mathrm{e}-3$ & $1.7381 \mathrm{e}-3$ & 0.0400 \\
\hline$v(2)$ & 0.0500 & $2.2582 \mathrm{e}-3$ & $2.2582 \mathrm{e}-3$ & 0.0500 \\
\hline$v(3)$ & 0.0601 & $2.5248 \mathrm{e}-3$ & $2.5277 e-3$ & 0.0600 \\
\hline$u(1)$ & 0.0536 & 0.0121 & 0.0126 & 0.0500 \\
\hline$u(2)$ & 0.0426 & $8.8039 e-3$ & $9.1847 e-3$ & 0.0400 \\
\hline$u(3)$ & 0.0265 & $4.8775 e-3$ & $5.0939 \mathrm{e}-3$ & 0.0250 \\
\hline$\rho(1)$ & 0.8076 & 0.0168 & 0.0169 & 0.8090 \\
\hline$\rho(2)$ & 0.5879 & 0.0309 & 0.0309 & 0.5878 \\
\hline$\rho(3)$ & 0.4530 & 0.0367 & 0.0367 & 0.4540 \\
\hline
\end{tabular}

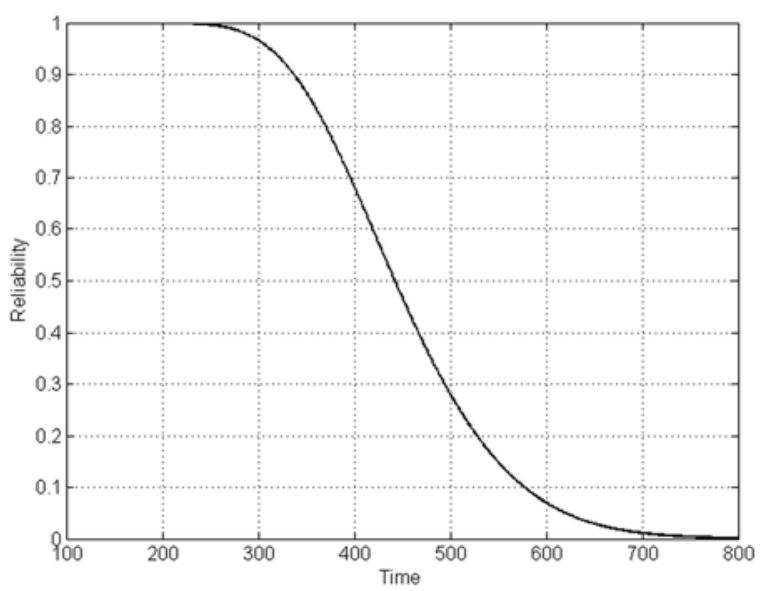

Fig. 2. The reliability of the system

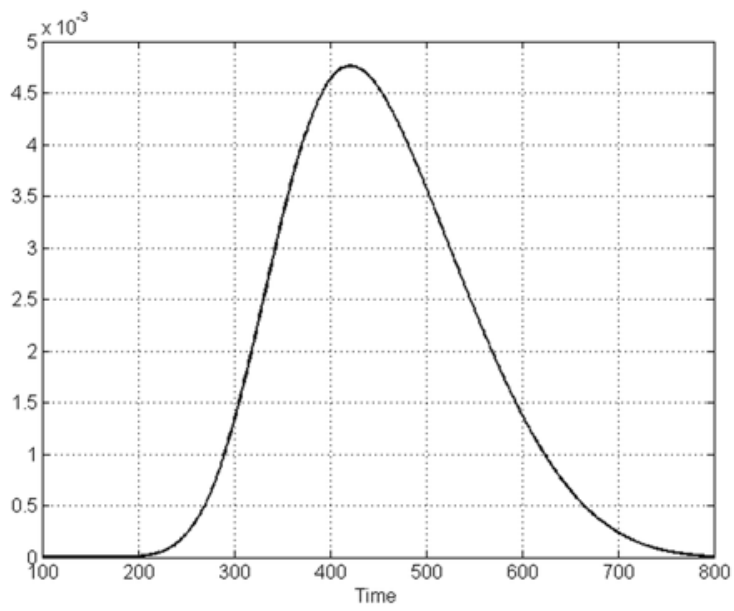

Fig. 3. The PDF of lifetime of the system

deviation, root mean squared error (RMSE) of the parameters can be obtained and listed in Table 1.

From Table 1, it is seen that the estimated parameters are very close to their true values. And it also reveals that RMSE of all the parameters are quite small. We, therefore, feel that the proposed model as well as the corresponding inferential method are performing very well, in this case.

Based on the estimates in Table 1, the reliability function and the corresponding PDF can be computed from (10) and (14) when $K=3$. The corresponding plots are illustrated in Figures 2 and 3, respectively.

\section{Concluding Remark}

The work of this paper is the extension of the results of Pan and Balakrishnan [9] that discussed the reliability model of bivariate degradation of products. We have introduced the lifetime distribution and associated inferential method of systems with multiple degradation measurements by assuming that all the degradation paths are governed by gamma processes. In this situation, we extend the work of Kundu et al. [4] and use a multivariate Birnbaum-Saunders distribution and its marginal distributions to approximate the reliability of the system. The inference of the model parameters is quite involved due to the complex form of the model and for this reason we used the Bayesian MCMC method for making inference. From the example in Section 5, we find that the proposed model as well as the inferential method for the model parameters work well.

\section{Acknowledgements}

This research was supported by the National Science Foundation of China under agreements 61273041 and 61304221 and supported by the Science Foundation of Hunan Province under agreements 14JJ3009. 
1. Barker C T, Newby M J. Optimal non-periodic inspection for a multivariate degradation model. Reliability Engineering and System Safety 2009; 94: 33-43, http://dx.doi.org/10.1016/j.ress.2007.03.015.

2. Birnbaum Z W, Saunders S C. A new family of life distributions. Journal of Applied Probability 1969; 6: 319-327, http://dx.doi. org $/ 10.2307 / 3212003$.

3. Crk V. Reliability assessment from degradation data. In: The annual reliability and maintainability symposium-product quality \& integrity 2004; Los Angeles: RAMS; 155-161.

4. Kundu D, Balakrishnan N, Jamalizadeh A. Bivariate birnbaum-saunders distribution and associated inference. Journal of Multivariate Analysis 2010; 101: 113-125, http://dx.doi.org/10.1016/j.jmva.2009.05.005.

5. Li J R, Coit D W, Elsayed A E. Reliability modeling of a series system with correlated or dependent component degradation processes. ICQR2MSE 2011; 388-393.

6. Mercier S, Meier-Hirmer C, Roussignol M. Bivariate gamma wear processes for track geometry modeling with application to intervention scheduling. Structure and Infrastructure Engineering 2012; 8:357-366, http://dx.doi.org/10.1080/15732479.2011.563090.

7. Nelsen P B. An Introduction to Copulas(2nd edn), New York, 2006.

8. Pan Z Q, Balakrishnan N. Constant-stress accelerated degradation model and inference. Communications in Statistics-Simulation and Computation 2011; 40: 259-269, http://dx.doi.org/10.1080/03610918.2010.534227.

9. Pan Z Q, Balakrishnan N. Reliability modeling of degradation of products with multiple performance characteristics based on gamma processes. Reliability Engineering and System Safety 2011; 96: 949-957, http://dx.doi.org/10.1016/j.ress.2011.03.014.

10. Peng W W, Huang H Z, Xie M, Yang Y J, Liu Y, A Bayesian Approach for System Reliability Analysis With Multilevel Pass-Fail, Lifetime and Degradation Data Sets. IEEE Transactions on Reliability 2013; 62: 689-699, http://dx.doi.org/10.1109/TR.2013.2270424.

11. Sari J K, Newby M J, Brombacher A C, Tang L C, Bivariate constant stress degradation model: LED lighting system reliability estimation with two-stage modeling. Quality and Reliability Engineering International 2009; 25: 1067-1084, http://dx.doi.org/10.1002/qre.1022.

12. Savage G J, Son Y K. The set-theory method for systems reliability of structures with degrading components. Reliability Engineering and System Safety 2011; 96: 108-116, http://dx.doi.org/10.1016/j.ress.2010.07.009.

13. Son Y K, Savage G J. Set theoretic formulation of performance reliability of multiple response time-variant systems due to degradations in system components. Quality and Reliability Engineering International 2007; 23: 171-188, http://dx.doi.org/10.1002/qre.783.

14. Wang P, Coit D W. Reliability prediction based on degradation modeling for systems with multiple degradation measures. In: The annual reliability and maintainability symposium - product quality \& integrity 2004; Los Angeles: RAMS; 302-307, http://dx.doi.org/10.1109/ rams.2004.1285465.

15. Wang Y P, Pham H. A multi-objective optimization of imperfect preventive maintenance policy for dependent competing risk systems with hidden failure. IEEE Transactions on Reliability 2011; 60: 770-781, http://dx.doi.org/10.1109/TR.2011.2167779.

16. Wang Y P, Pham H. Modeling the dependent competing risks with multiple degradation processes and random shock using time-varying copulas. IEEE Transactions on Reliability 2012; 61:13-22, http://dx.doi.org/10.1109/TR.2011.2170253.

17. Wang Z L, Huang H Z, Li Y F, Xiao N C, An Approach to Reliability Assessment Under Degradation and Shock Process. IEEE Transactions on Reliability 2011; 60: 852-863, http://dx.doi.org/10.1109/TR.2011.2170254.

18. Wang Z L, Huang H Z, Du L, Reliability Analysis on Competitive Failure Processes Under Fuzzy Degradation Data. Applied Soft Computing 2011; 11:2964-2973, http://dx.doi.org/10.1016/j.asoc.2010.11.018.

19. Xu D, Zhao W B. Reliability prediction using multivariate degradation data. In: The annual reliability and maintainability symposiumproduct quality \& integrity 2005; Alexandria: RAMS; 337-341.

20. Zhou J L, Pan Z Q, Sun Q. Bivariate degradation modeling based on gamma process. WCE 2010; London; III: $1783-1788$.

\author{
Zhengqiang PAN \\ Jing FENG \\ Quan SUN \\ College of Information System and Management \\ National University of Defense Technology \\ Sanyi Avenue, Changsha, China
}

E-mail: panzhq.yy@hotmail.com, panzhengqiang@nudt.edu.cn 